\title{
Comparing the first and second waves of COVID-19 in a
}

\section{tertiary university hospital in Barcelona [version 1; peer}

\section{review: 2 approved]}

\author{
Yolima Cossio(i1,2, Marta-Beatriz Aller1,2, Maria José Abadias1,2, \\ Jose-Manuel Domínguez ${ }^{1}$, Maria-Soledad Romea1,2, Maria-Àngels Barba1,2, \\ Maria-Isabel Rodríguez ${ }^{1}$, Antonio Roman 1,2, Albert Salazar ${ }^{1,2}$ \\ ${ }^{1}$ Hospital Universitari Vall d'Hebron, Barcelona, Spain \\ ${ }^{2}$ Health Services Research Group, Institut de Recerca Vall d'Hebron, Barcelona, Spain
}

V1 First published: 24 Nov 2021, 10:1197

https://doi.org/10.12688/f1000research.73988.1

Latest published: 24 Nov 2021, 10:1197

https://doi.org/10.12688/f1000research.73988.1

\section{Abstract \\ Background:}

Hospitals have constituted the limiting resource of the healthcare systems for the management of the COVID-19 pandemic. As the pandemic progressed, knowledge of the disease improved, and healthcare systems were expected to be more adapted to provide a more efficient response. The objective of this research was to compare the flow of COVID-19 patients in emergency rooms and hospital wards, between the pandemic's first and second waves at the University Hospital of Vall d'Hebron (Barcelona, Spain), and to compare the profiles, severity and mortality of COVID-19 patients between the two waves.

\section{Methods:}

A retrospective observational analysis of COVID-19 patients attending the hospital from February 24 to April 26, 2020 (first wave) and from July 24, 2020, to May 18, 2021 (second wave) was carried out. We analysed the data of the electronic medical records on patient demographics, comorbidity, severity, and mortality.

\section{Results:}

The daily number of COVID-19 patients entering the emergency rooms (ER) dropped by $65 \%$ during the second wave compared to the first wave. During the second wave, patients entering the ER were significantly younger (61 against 63 years old $p<0.001)$ and less severely affected (39\% against $48 \%$ with a triage level of resuscitation or emergency; $p<0.001)$. ER mortality declined during the second wave ( $1 \%$ against $2 \% ; p<0.000$ ). The daily number of hospitalised COVID-19 patients dropped by $75 \%$ during the second wave. Those hospitalised during the second wave were more severely affected ( $20 \%$ against $10 \% ; p<0.001)$ and were referred to the intensive care unit (ICU) more frequently $(21 \%$ against $15 \% ; p<0.001)$. Inpatient mortality showed no

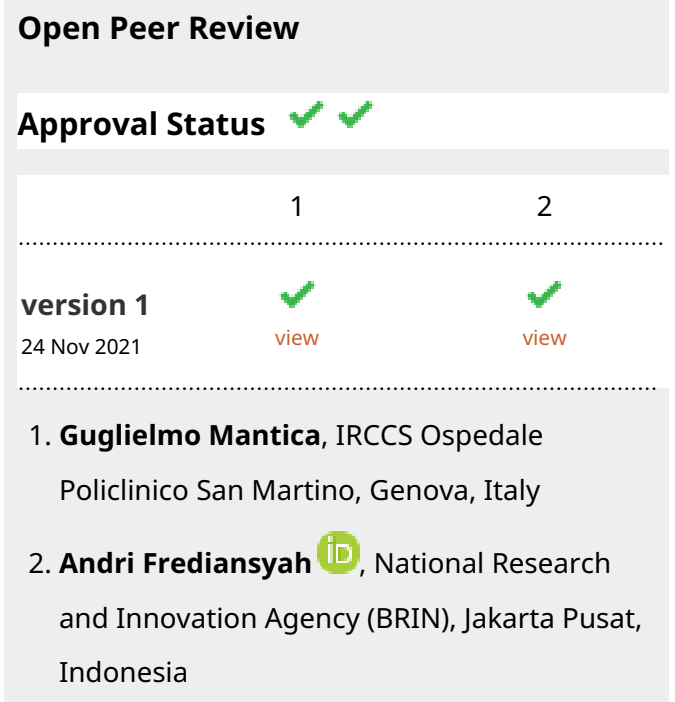

Any reports and responses or comments on the article can be found at the end of the article. 
significant difference between the two waves.

\section{Conclusions:}

Changes in the flow, severity and mortality of COVID-19 patients entering this tertiary hospital during the two waves may reflect a better adaptation of the health care system and the improvement of knowledge on the disease.

\section{Keywords}

covid-19, hospital management, tertiary hospital

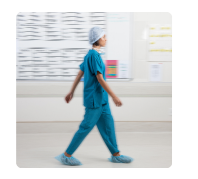

This article is included in the Health Services

gateway.

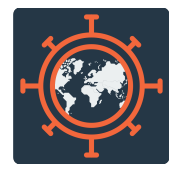

This article is included in the Emerging Diseases

and Outbreaks gateway.

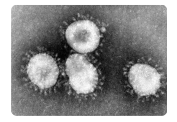

This article is included in the Coronavirus

collection.

Corresponding author: Yolima Cossio (ycossio@vhebron.net)

Author roles: Cossio Y: Conceptualization, Project Administration, Supervision, Writing - Original Draft Preparation, Writing - Review \& Editing; Aller MB: Formal Analysis, Methodology, Writing - Original Draft Preparation; Abadias MJ: Writing - Review \& Editing;

Domínguez JM: Writing - Review \& Editing; Romea MS: Writing - Review \& Editing; Barba MÀ: Writing - Review \& Editing; Rodríguez MI

: Writing - Review \& Editing; Roman A: Formal Analysis, Methodology, Supervision, Validation, Writing - Original Draft Preparation,

Writing - Review \& Editing; Salazar A: Writing - Review \& Editing

Competing interests: No competing interests were disclosed.

Grant information: The author(s) declared that no grants were involved in supporting this work.

Copyright: $\odot 2021$ Cossio $Y$ et al. This is an open access article distributed under the terms of the Creative Commons Attribution License, which permits unrestricted use, distribution, and reproduction in any medium, provided the original work is properly cited.

How to cite this article: Cossio Y, Aller MB, Abadias MJ et al. Comparing the first and second waves of COVID-19 in a tertiary university hospital in Barcelona [version 1; peer review: 2 approved] F1000Research 2021, 10:1197

https://doi.org/10.12688/f1000research.73988.1

First published: 24 Nov 2021, 10:1197 https://doi.org/10.12688/f1000research.73988.1 


\section{Introduction}

The COVID-19 pandemic has challenged healthcare systems around the world. ${ }^{1}$ Hospitals with the capacity to undertake critical patients in intensive care units (ICUs) have constituted the limiting resource of the healthcare systems for the management of the pandemic. ICUs possess essential equipment such as mechanical ventilators and monitoring devices that have enabled the provision of vital support to COVID-19 patients developing a severe form of the disease. ${ }^{2}$ As a consequence, hospitals, especially tertiary ones, have had to reorganize their activity to make available the largest number of beds for treating COVID-19 patients, including ICU beds, to manage the progressive surge in demand, while trying to maintain essential hospital services. ${ }^{3}$

As many other countries, Spain has been seriously affected by the COVID-19 pandemic, and a significant number of confirmed cases and deaths have been reported. The first case of COVID-19 was confirmed on January 31 in La Gomera in the Canary Islands. Six weeks later, on March 14, Spain declared a state of emergency and imposed rigorous lockdown measures to the population, ${ }^{4}$ that enabled a sustained decrease in the accumulated incidence of COVID-19 in the population. ${ }^{5,6}$ After the end of the first pandemic wave, the measures to contain the disease were relaxed during the summer, and the incidence of cases began to rise slowly in some Spanish regions such as Catalonia, starting the second wave.

Although we do not have conclusive data about a potential increase of aggressiveness of the virus, both the virus and our knowledge of the disease have evolved over time, as well as the adaptation of health systems to cope with the pandemic. We could therefore expect differences in the number, severity and outcomes of patients admitted in healthcare services, including tertiary hospitals. Several studies pointed out differences in the epidemiological and clinical behaviour of the pandemic waves in terms of severity, transmission and dissemination of the virus. ${ }^{7,8}$ Incidence levels showed different patterns between waves, with the number of cases being higher in the second wave in comparison to the first one, probably as a consequence of the shortage of diagnostic testing in the first wave, causing declared numbers underestimating real numbers. ${ }^{8}$ Moreover, the second wave showed a behaviour of multiple peaks that may reflect the mobility of the population, ${ }^{9}$ while the incidence decrease may be connected to an increase in containment measures. ${ }^{9,10}$ There have been significant improvements in the clinical knowledge of the disease that may have affected the flow of hospitalized patients, as well as their severity and outcome. These include a better approach to treatment, ${ }^{11,12}$ and a better understanding of prognostic factors ${ }^{13}$ that may have served to optimize treatment, and resource management strategies in the care of COVID-19 patients. Finally, the adaptation of healthcare systems may have also modified the profile and flow of patients entering the hospitals. In Catalonia, there has been a progressive adaptation of health services to better allocate patients according to the complexity of care needed. ${ }^{14}$ While in the first wave COVID-19 care was mainly hospitalcentered, with scarce territorial coordination, there has been a progressive increase in coordination between healthcare levels, including the definition of clear roles and care protocols for the primary care. ${ }^{15}$ In addition, key strategies have been implemented to protect vulnerable groups, such as the systematic COVID-19 screening in nursing homes ${ }^{16}$ and vaccination campaigns. ${ }^{17}$

Tertiary hospitals are expected to treat complex patients requiring a more specialized care. During the first wave, hospitals have been the first contact with the healthcare system for many COVID-19 patients, almost resulting in its collapse. As the pandemic progressed, knowledge of the disease improved and healthcare systems adapted to provide a more efficient response. As a consequence, tertiary hospitals might have mainly received the most severe COVID-19 cases. However, few data are available to analyse how the profile and severity of COVID-19 patients entering tertiary hospitals has evolved over time. The aim of this study was to compare the flow, profile, severity and mortality of COVID-19 patients, during the first and second waves of the pandemic at the University Hospital of Vall d'Hebron (Barcelona).

\section{Methods}

Ethical considerations and consent

This study was approved by the Clinical Research Ethics Committee at the Hospital Universitari Vall d'Hebron from Barcelona (Spain), in session Number 497 on 30 July 2021. No consent from the participants was required for this study since this is a retrospective research study based on anonymous and de-identified data.

\section{Study design and setting}

This retrospective, exploratory, observational analysis compared demographic, clinical and outcome data of COVID-19 patients attending the Vall d'Hebron University Hospital (HUVH), from February 24 to April 26, 2020 (first wave) and from July 24, 2020 to May 18, 2021 (second wave). The HUVH is a 1,100-bed university hospital in Barcelona, the second largest hospital in Spain, and is part of the Catalan Public Healthcare System, which provides universal coverage to the population. The hospital works in close coordination with other healthcare organisations in the region, including one secondary care hospital, three intermediate care centres and 19 primary care centres. The HUVH hosts over 7,500 healthcare professionals and covers a population of about 450,000 people. 


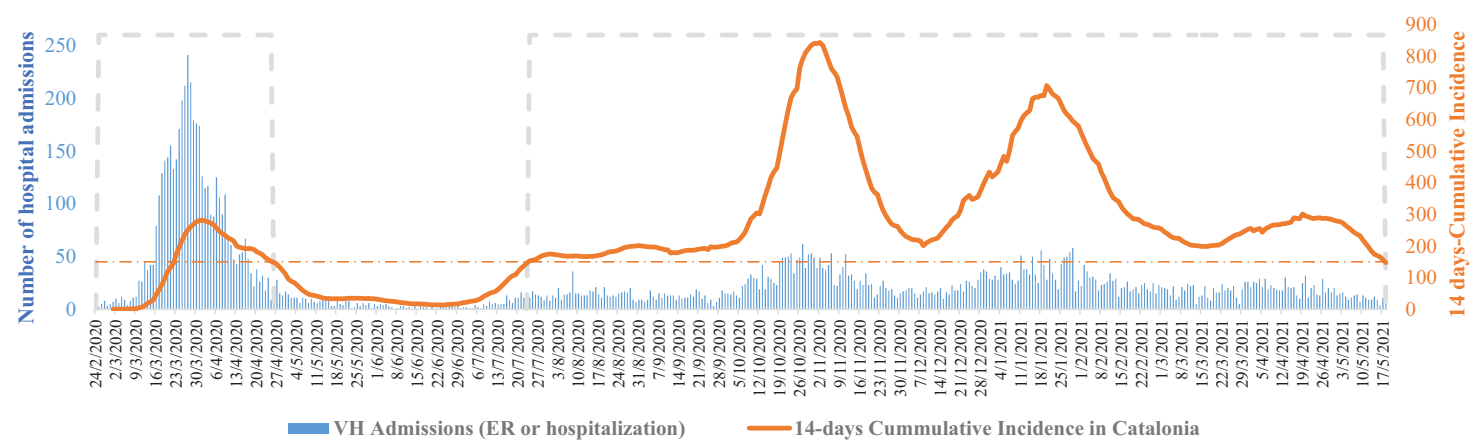

Figure 1.14 days-CI in Catalonia and COVID-19 hospital admissions (emergency or hospitalization). The orange dashed line shows the cumulative incidence threshold that has been defined as a very high-risk situation in Spain. The blue dashed line represents the two waves of the pandemic in Catalonia according to the criteria defined in the article.

Waves have been defined based on the 14-day cumulative incidence (CI) in Catalonia, which is published by the Catalan Health Department, and is defined as the total number of confirmed cases in the prior 14 days/100,000 population. A CI value equal to or lower than 150 has been set to define the boundaries of the waves, as this value was considered the threshold for a high-risk situation in Spain according to the health authorities. ${ }^{19}$ We defined February 24, 2020 as the start date of the first wave, when the first case of COVID-19 was reported in Catalonia (Figure 1). The peak of CI during the first wave was on April 1, with a value of 281.26, and the end of the first wave was on April 26, when the CI fell below 150 (147.85). The second wave started on July 24, when the CI exceeded 150 (153.4), reached its peak on October 31 (840.27), and ended on May 18, when the CI fell below 150 (146.89). Data was extracted and frozen on August 16, 2021.

\section{Participants}

The study included 8,684 distinct COVID-19 patients who attended the emergency rooms (ER) and/or were hospitalised. Cases were identified using the ICD-10-CM diagnostic codes recorded in the hospital-discharge data: B34.2 and B97.29 (from February 2020) and ICD-10 code U07.1 (from July 1, 2020). Discharge diagnoses of hospitalised patients were registered by specialised coders. To guarantee that we were analysing and comparing data from patients affected by the COVID-19 disease, we only included: i) patients whose primary diagnosis was COVID-19 or, ii) patients with a secondary COVID-19 diagnosis following a first diagnosis of a respiratory system disease (ICD-10-CM code starting by J), or who were described with a Diagnosis Related Groups (DRG) 137 (Infections in major lung inflammations) or 139 (other pneumonia). The selection criteria for the patients attending the ER was to have a confirmed COVID-19 diagnosis, regardless of whether it was a primary or secondary diagnosis.

\section{Variables and data sources}

To compare the inpatient and emergency flow activity of the HUVH between waves, we created an indicator measuring the total daily number of patients entering the hospital. To compare the characteristics of COVID-19 patients who entered the hospital emergency department and/or were hospitalized, we used data on patient demographics (sex and age) and comorbidity (the adjusted morbidity groups [GMA]). GMA is a validated morbidity measurement developed and adapted to the Spanish Healthcare System that classifies the population into seven morbidity groups, taking into account the typology of their diseases (acute, chronic, or oncological), and in the case of chronic disease, identifying whether it is a single or a multimorbidity. Two additional groups refer to pregnant/childbirth women and populations without previous pathologies. $^{20,21}$

To compare the severity of patients attending the ER, we included the type of emergency as defined by the structured triage system for emergency services implemented in Catalonia, which is based on the Australian-Canadian triage systems, and divides the emergencies into five groups: resuscitation, emergent, urgent, less urgent and non-urgent. ${ }^{22}$ The severity of hospitalised patients' state was analysed according to the following variables: first, the severity of the episode, as measured by the weight of the diagnosis-related groups (APR- DRG, version 36) and its severity. Changes in the DRG weights of COVID-19-related diagnosis occurred in July 2020, due to 1) the use of the U07.1 diagnosis code for COVID-19,2) the number of patients accessing the ICU and 3) the overall length of stay (LOS) during the hospitalization and the ICU-specific LOS. Finally, to compare the mortality rates between the two waves, we included three variables: overall mortality during the hospitalization, three-day mortality and mortality of patients who entered the ICU. 
Data was obtained from the electronic medical records and extracted using structured query language (SQL), to create and anonymized database. The data collection period was defined as per the hospital admission date and only discharged patients' data was included.

Data analysis

Continuous variables were reported as mean and standard deviation (SD), and median and interquartile range (IQR). Categorical variables were presented as frequency rates and percentages. Continuous variables were compared using the Mann-Whitney U-test, while comparisons of categorical variables were performed using Chi square tests. All analyses were performed using STATA 13.0 (STATA Corp.). A p-value lower than 0.05 was considered as statistically significant.

\section{Results}

Emergency care

A $65 \%$ drop in the daily number of COVID-19 patients entering the ER was observed during the second wave compared to the first wave (17.5 against 49.8 patients per day on average, respectively). The distribution of ER admissions is shown in Figure 2. During the second wave, patients entering the ER were significantly younger (median age of 61 against 63) (Table 1). No significant difference was observed in the percentage of women entering the ER (47.0\% and $47.6 \%$ during the second and first waves, respectively). During the second wave, patients entering the ER were less severely affected (39.1\% against $48.5 \%$, with a triage level of resuscitation or emergency), and the ER mortality significantly declined from $2.3 \%$ to $1.2 \%$.

\section{Inpatient care}

A 75\% drop in daily hospitalised COVID-19 patients was observed during the second wave compared to the first wave (7.9 against 32.0 mean patients per day, respectively). The distribution of hospital admissions is shown in Figure 2. No significant differences were found when comparing the median age (Table 2); however, patients older than 80 represented a lower percentage among hospitalised patients during the second wave in comparison to the first wave (8.2\% against $11.6 \%$ ), while patients younger than 18 represented a higher percentage during the second wave (2.7\% against $1.7 \%)$. The percentage of hospitalized women was significantly lower during the second compared to the first wave (38.8\% against 43.9\%). In terms of basal morbidity, the most significant difference between waves was found in the population with acute pathologies, which increased during the second wave (5.6\% against $2.1 \%$ ).
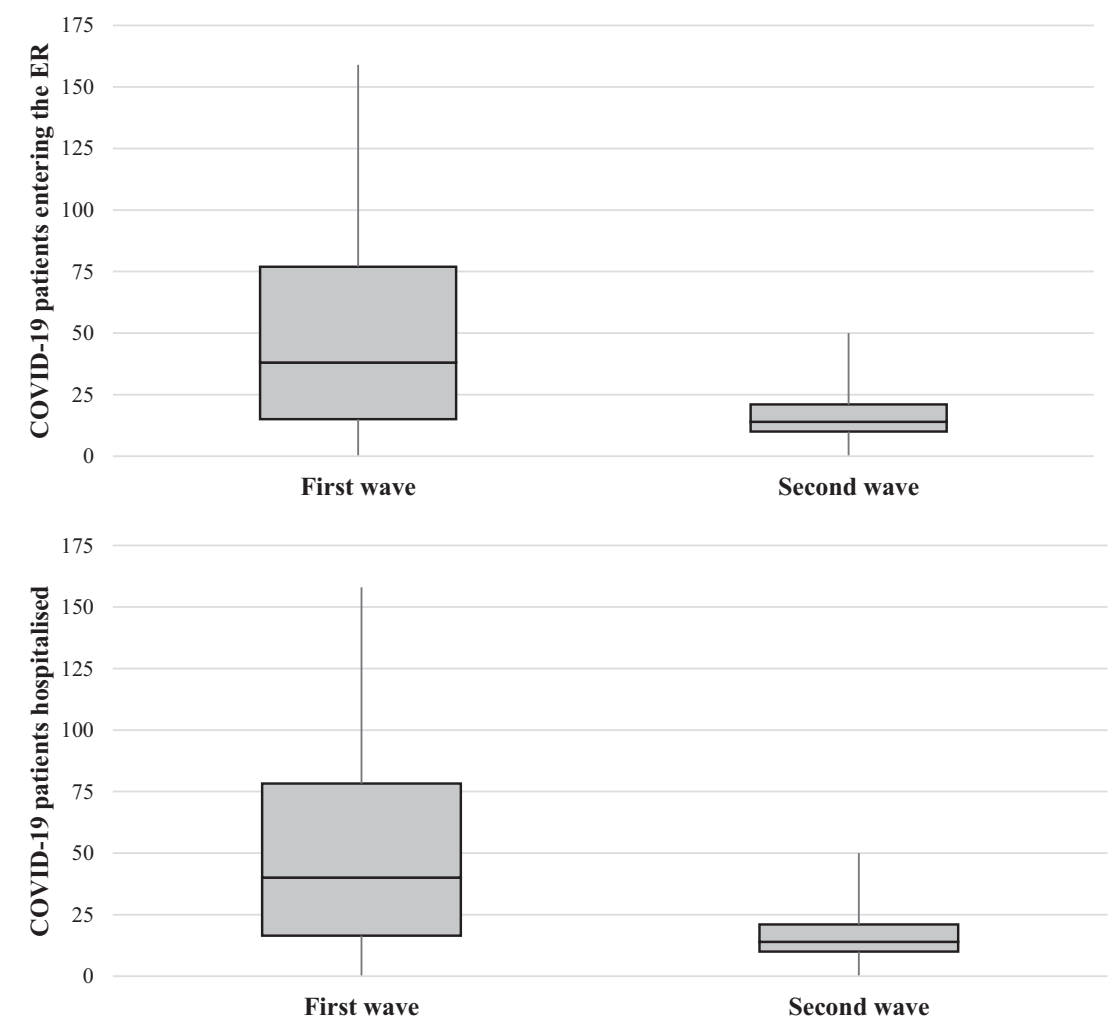

Figure 2. Distribution of the number of hospital admissions per day during the first and second waves. 
Table 1. Characteristics, type of emergency and mortality of COVID-19 patients entering the hospital. IQR = interquartile range; GMA = adjusted mortality group. Bold p-values represent statistically significant values.

\begin{tabular}{|c|c|c|c|}
\hline & $\begin{array}{l}\text { First wave } \\
\text { (Feb 24, 2020 - Apr 26, 2020) }\end{array}$ & $\begin{array}{l}\text { Second wave } \\
\text { (Jul 24, } 2020 \text { - May 18, 2021) }\end{array}$ & p-value \\
\hline $\mathrm{n}$ episodes & 3037 & 5043 & \\
\hline \multicolumn{4}{|c|}{ Demographic characteristics of patients } \\
\hline \multicolumn{4}{|l|}{ Sex } \\
\hline Women (n (\%)) & $1447(47.6 \%)$ & $2375(47.0 \%)$ & 0.631 \\
\hline \multicolumn{4}{|l|}{ Age } \\
\hline Mean (DE) & $62.4(19.4)$ & $58.4(22.7)$ & \\
\hline Median (IQR) & $63(29)$ & $61(34)$ & 0.000 \\
\hline$<18$ years $(\mathrm{n}(\%))$ & $48(1.58 \%)$ & $272(5.39 \%)$ & 0.000 \\
\hline $18-35$ years $(n(\%))$ & $209(6.88 \%)$ & $512(10.1 \%)$ & 0.000 \\
\hline $35-49$ years $(n(\%))$ & $543(17.8 \%)$ & $963(19.0 \%)$ & 0.174 \\
\hline $50-64$ years $(n(\%))$ & $789(25.9 \%)$ & $1137(22.5 \%)$ & 0.000 \\
\hline $65-79$ years $(n(\%))$ & $779(25.6 \%)$ & $1127(22.3 \%)$ & 0.001 \\
\hline$>80$ years $(\mathrm{n}(\%))$ & $669(22.0 \%)$ & $1032(20.4 \%)$ & 0.095 \\
\hline \multicolumn{4}{|l|}{ Morbidity } \\
\hline Morbidity groups (GMA) & 2992 & 4967 & \\
\hline No previous pathologies & $137(4.57 \%)$ & $235(4.73 \%)$ & 0.757 \\
\hline Acute pathologies & $50(1.67 \%)$ & $257(5.17 \%)$ & 0.000 \\
\hline Pregnancy and childbirth & $17(0.56 \%)$ & $30(0.60 \%)$ & 0.841 \\
\hline Chronic pathologies in 1 system & $237(7.92 \%)$ & $449(9.03 \%)$ & 0.086 \\
\hline Chronic pathologies in 2 or 3 systems & $672(22.4 \%)$ & $1025(20.6 \%)$ & 0.054 \\
\hline Chronic pathologies in $>3$ systems & $1638(54.7 \%)$ & $2567(51.6 \%)$ & 0.008 \\
\hline Active neoplasm & $124(4.14 \%)$ & $190(3.82 \%)$ & 0.477 \\
\hline Type of emergency & 2992 & 4967 & \\
\hline Resuscitation + emergency ( $(\%)$ ) & $1453(48.5 \%)$ & $1944(39.1 \%)$ & \multirow[t]{3}{*}{0.000} \\
\hline Urgency (n (\%)) & $1307(43.6 \%)$ & $2643(53.2 \%)$ & \\
\hline Minor urgency + non urgent (n (\%)) & $232(7.75 \%)$ & $380(7.65 \%)$ & \\
\hline \multicolumn{4}{|l|}{ Mortality } \\
\hline Mortality (n(\%)) & $70(2.30 \%)$ & $61(1.20 \%)$ & 0.000 \\
\hline
\end{tabular}

The median severity of the hospitalizations significantly increased during the second wave, with those patients hospitalised during the second wave being more severely affected $(20.2 \%$ had the highest DGR severity score compared to $10.0 \%$ during the first wave) and were admitted more frequently to the ICU (20.6\% against $15.3 \%)$. The median length of stay significantly increased during the second wave (6.6 against 5.9 days during the first wave) while the median ICU length of stay was significantly lower during the second wave ( 9.8 against 15.2 days during the first wave). Finally, there were no significant differences in inpatient nor in ICU mortality between waves, although the three-day-mortality rate was significantly lower during the second wave (2.1\% against $3.1 \%$ during the first wave).

\section{Discussion}

The study shows differences in the flow and characteristics of hospitalized patients between the first and second waves of the COVID-19 pandemic at the HUVH. While the daily flow of patients entering the hospital during the second wave was lower, hospitalized patients were more severely affected, and a higher proportion were admitted to the ICU. However, during the second wave, we did not observe any increase of the overall mortality among hospitalized patients, despite the increase in severity. 
Table 2. Characteristics, severity and mortality of COVID-19 hospitalised patients. IQR = interquartile range. Bold p-values represent statistically significant values.

\begin{tabular}{|c|c|c|c|}
\hline & $\begin{array}{l}\text { First wave } \\
\text { (February 24, } 2020 \text { - } \\
\text { April 26, 2020) }\end{array}$ & $\begin{array}{l}\text { Second wave } \\
\text { (July 24, 2020 - } \\
\text { May 18, 2021) }\end{array}$ & p-value \\
\hline n episodes & 2013 & 2367 & \\
\hline \multicolumn{4}{|l|}{ Demographic characteristics of patients } \\
\hline \multicolumn{4}{|l|}{ Sex } \\
\hline Women (n (\%)) & $885(43.9 \%)$ & $920(38.8 \%)$ & 0.001 \\
\hline \multicolumn{4}{|l|}{ Age } \\
\hline Mean (DE) & $59.6(17.3)$ & $58.7(17.1)$ & \\
\hline Median (IQR) & $60(23)$ & $61(22)$ & 0.296 \\
\hline$<18$ years $(\mathrm{n}(\%))$ & $35(1.7 \%)$ & $63(2.7 \%)$ & 0.040 \\
\hline $18-35$ years $(n(\%))$ & $115(5.7 \%)$ & $129(5.4 \%)$ & 0.705 \\
\hline $35-49$ years $(n(\%))$ & $389(19.3 \%)$ & $471(19.8 \%)$ & 0.634 \\
\hline $50-64$ years $(n(\%))$ & $676(33.5 \%)$ & $778(32.8 \%)$ & 0.617 \\
\hline $65-79$ years $(n(\%))$ & $564(28.0 \%)$ & $732(30.9 \%)$ & 0.036 \\
\hline$>80$ years $(\mathrm{n}(\%))$ & $234(11.6 \%)$ & $194(8.2 \%)$ & 0.000 \\
\hline \multicolumn{4}{|l|}{ Morbidity } \\
\hline Morbidity groups (GMA) & 1895 & 2245 & \\
\hline No previous pathologies (n (\%)) & $94(4.96 \%)$ & $87(3.87 \%)$ & 0.099 \\
\hline Acute pathologies (n (\%)) & $40(2.11 \%)$ & $125(5.56 \%)$ & 0.000 \\
\hline Pregnancy and childbirth (n (\%)) & $11(0.58 \%)$ & $4(0.17 \%)$ & 0.033 \\
\hline Chronic pathologies in 1 system (n (\%)) & $175(9.23 \%)$ & $208(9.26 \%)$ & 0.913 \\
\hline Chronic pathologies in 2 or 3 systems (n (\%)) & $503(26.5 \%)$ & $534(23.7 \%)$ & 0.060 \\
\hline Chronic pathologies in > 3 systems (n (\%)) & $992(52.3 \%)$ & $1184(52.7 \%)$ & 0.625 \\
\hline Active neoplasm (n (\%)) & $80(4.22 \%)$ & $103(4.58 \%)$ & 0.534 \\
\hline Severity of the episode & 2018 & 1847 & \\
\hline Severity, weigh (DRG) (mean (DE)) & $1.1(1.8)$ & $1.4(1.9)$ & \\
\hline Severity, weight (DRG) (median (IQ)) & $0.4(0.2)$ & $0.7(0.2)$ & 0.000 \\
\hline Higher degree of severity (n (\%)) & $202(10.0 \%)$ & $479(20.2 \%)$ & 0.000 \\
\hline \multicolumn{4}{|l|}{ ICU care } \\
\hline n episodes (n (\%)) & $309(15.3 \%)$ & $488(20.6 \%)$ & 0.000 \\
\hline \multicolumn{4}{|l|}{ Lenght of stay } \\
\hline Lenght of stay hospitalization (mean (DE)) & $10.1(13.7)$ & $11.3(14.5)$ & \\
\hline Lenght of stay hospitalization (median (IQR)) & $5.9(5.8)$ & $6.6(8.9)$ & 0.007 \\
\hline Lenght of stay ICU (mean (DE)) & $19.3(17.3)$ & $16.6(17.1)$ & \\
\hline Lenght of stay ICU (median (IQR)) & $15.2(18.5)$ & $9.8(19.1)$ & 0.003 \\
\hline \multicolumn{4}{|l|}{ Global mortality } \\
\hline Mortality (n (\%)) & $199(9.88 \%)$ & $221(9.33 \%)$ & 0.539 \\
\hline 3-days mortality (n (\%)) & $63(20.3 \%)$ & $48(9.8 \%)$ & 0.021 \\
\hline \multicolumn{4}{|l|}{ Mortality of ICU admitted patients } \\
\hline Mortality (n (\%)) & $61(19.7 \%)$ & $64(13.1 \%)$ & 0.518 \\
\hline
\end{tabular}


The lower daily flow of COVID-19 patients entering the hospital during the second wave contrasts with the increased incidence officially reported in the population during this period. ${ }^{18}$ This result reflects the adaptation of the health system to tackle the pandemic, with a greater involvement of other healthcare levels in the diagnosis and management of COVID-19 patients. ${ }^{14}$ During the first wave, hospitals were challenged with the need to simultaneously provide healthcare to a high number of COVID-19 patients, with hospitals centralizing most of the healthcare activity, and reaching a situation close to the collapse. However, the second wave benefited from a more experienced management and the redistribution of the responsibilities at various levels, stratifying patients and referring them to hospitals only upon need. ${ }^{15,23}$ In addition, during the first wave, there was a limited availability of real-time diagnostic tests in primary care, and the diagnosis of COVID-19 was mainly conducted in hospitals, especially on symptomatic patients. ${ }^{24}$ Conversely, during the second wave, population screenings were conducted and a rapid diagnosis of COVID-19 was performed mainly at the primary care level. These adaptations of the healthcare system during the second wave may have led to a lower daily flow of patients requiring hospitalization.

The severity of COVID-19 patients entering the ER and getting hospitalized differed between waves. COVID-19 patients entering the ER during the second wave were less severely ill, whilst the opposite was observed in hospitalizations. The lack of clinical knowledge on the disease and the messages communicated to the population about hospital collapse during the first wave may have contributed to these differences, as well as significant improvements in the coordination of health services produced during the second wave. Regarding the severity of cases in the ER, we measured this parameter according to the structured triage system implemented in Catalonia. ${ }^{22}$ It is therefore possible that during the first wave, the lack of knowledge of the disease by the personnel responsible for ER triage led to registering patients with a higher level of urgency. During the first wave the population was encouraged to stay at home. This, added to the population's fear of infection, may have resulted in people being more likely to seek emergency care only when there was a more severe presentation of the disease, with almost no alternatives to seeking care outside of hospitals. Regarding the severity of hospitalised patients, other factors may be contributing to the observed differences, probably related to the adaptation of the healthcare system. In fact, the higher percentage of COVID-19 patients requiring ICU care and being categorised with the highest degree of severity at discharge, may be reflecting the participation of other healthcare levels in the management of COVID-19 that was observed during the second wave $\mathrm{e}^{14,23}$; this may have resulted in a better stratification of the patients referred to the hospital, depending on the severity of their symptoms. An increased knowledge on prognostic factors may have also affected the severity of hospitalised patients. While during the first wave any patient with a radiologically-diagnosed pneumonia was hospitalised, during the second wave the hospital implemented protocols to hospitalize patients with a COVID-19 diagnostic according to their prognostic factors. Finally, the observed differences are not expected to be caused by differences in the virus, as new strains of the SARS-CoV-2 virus were detected late in Spain. ${ }^{25}$

In addition to differences in the severity of patients entering the hospital between waves, we observed differences in these patients' profiles in terms of age, sex and comorbidities. First, younger patients were admitted into the ER during the second wave, which is consistent with the lower severity reported in this period. In addition, during the second wave a lower percentage of COVID-19 patients older than 80 and patients without any described comorbidity were hospitalised. The large number of older patients coming from nursing homes during the first wave, most of which presenting a severe condition, together with actions to improve the protection of this population after the first wave $\mathrm{e}^{26}$ and their prompt vaccination around mid-January $2021,{ }^{27}$ could explain the differences in age distribution between the two waves. Finally, a lower percentage of women were hospitalized during the second wave compared to the first one. As previously described, being male correlates with a more severe COVID-19 profile. ${ }^{28}$ The increased severity in the hospitalized patients observed during the second wave is correlated with the lower percentage of hospitalized women.

Finally, we did not observe any increase of the overall mortality during the second wave, despite the greater severity of hospitalised patients. Significant improvements in the clinical knowledge of the disease may contribute to explain this result. A large number of drugs have been tested from the start of the pandemic around the world in order to identify effective therapeutic alternatives. ${ }^{29}$ This led to the identification of a few safe and effective therapeutic approaches in severe cases of the disease, including anticoagulant therapy and corticosteroids. ${ }^{11,12}$

This study has some limitations, as it used a limited number of parameters for the analysis. Further analysis including the type of treatments received during the hospitalization, or more detailed information on previous conditions would help gain a better understanding of the differences in the profiles of COVID-19 patients admitted between the pandemic phases, as well as differences in hospital management strategies.

\section{Conclusions}

This comparative study shows a less intensive activity in the second wave of the COVID-19 pandemic in both the ER frequentation and hospitalizations, but more severe profiles of patients receiving inpatient care compared to the 
first wave. Although severity in hospitalised patients increased over time, no significant differences were observed in the overall mortality rate during the hospitalization. The results may be reflecting a better adaptation of the overall healthcare system, including a better adaptation and coordination of the healthcare services, better understanding of prognostic factors and treatment, and the success of the different strategies to protect more vulnerable populations, including vaccination and protection of the elderly in nursing homes. These results may be helpful to improve current knowledge on the evolution of the pandemics in a tertiary hospital, the most limiting resource in the healthcare system, and may shed light on the adaptation processes of the healthcare systems and their results for incoming waves.

\section{Data availability}

Underlying data

DRYAD: Comparing the first and second waves of COVID-19 in a tertiary university hospital in Barcelona, https://doi. org/10.5061/dryad.0k6djhb1d. ${ }^{30}$

This project contains the following underlying data:

- Files_manuscript_COVID12Waves_20210910_.xlsx, that includes: 1) table describing the number of hospital admissions by day and the 14 days accumulated incidence in Catalonia; 2) table describing the profile of patients accessing emergency care, the type of emergency and mortality; and 3) table with data describing the profile of hospitalised patients, and details on their length of stay, UCI stay, severity, and mortality.

- Readme_COVID12Waves.xlsx (a detailed description of variables included in the files).

Data are available under the terms of the Creative Commons Zero "No rights reserved" data waiver (CC0 1.0 Public domain dedication).

\section{Acknowledgments}

We want to acknowledge Dr. Pascal Kahlem and Pau Berenguer Molins from Scientific Network Management S.L. (Spain) for their support in the elaboration of the manuscript. The authors would also like to thank all the Vall d'Hebron staff for the effort, understanding and dedication they have had in these difficult times.

1. Haldane V, De Foo C, Abdalla SM, et al.: Health systems resilience in managing the COVID-19 pandemic: lessons from 28 countries. Nat. Med. 2021; 27: 964-980. 2021.

Publisher Full Text

2. OECD/European Union: Health at a Glance: Europe 2020: State of Health in the EU Cycle. Paris: OECD Publishing; 2020. Publisher Full Text

3. World Health Organization: Maintaining essential health services: operational guidance for the COVID-19 context. World Health Organization; 2020. Published 2020. Accessed October 29, 2021. Reference Source

4. Real Decreto 463/2020: de $\mathbf{1 4}$ de marzo, por el que se declara el estado de alarma para la gestión de la situación de crisis sanitaria ocasionada por el COVID-19. Published 2020. Accessed July 7, 2021. Reference Source

5. Redondo-Bravo L, Moros MJS, Sanchez EVM, et al.: The first wave of the COVID-19 pandemic in Spain: characterisation of cases and risk factors for severe outcomes, as at 27 April 2020. Eurosurveillance. 2020; 25(50): 2001431.

6. Santamaría L, Hortal J: COVID-19 effective reproduction number dropped during Spain's nationwide dropdown, then spiked at lower-incidence regions. Sci. Total Environ. 2021; 751: 142257. PubMed Abstract | Publisher Full Text | Free Full Text

7. Long SW, Olsen RJ, Christensen PA, et al.: Molecular architecture of early dissemination and massive second wave of the SARS-CoV-2 virus in a major metropolitan area. MBio. 2020; 11(6): e02707-e02720. Publisher Full Text

8. Soriano V, Ganado-Pinilla P, Sanchez-Santos M, et al.: Main differences between the first and second waves of COVID-19 in
Madrid, Spain. Int. J. Infect. Dis. 2021; 105: 374-376. PubMed Abstract | Publisher Full Text | Free Full Text

9. Linka K, Goriely A, Kuhl E: Global and local mobility as a barometer for COVID-19 dynamics. Biomech. Model. Mechanobiol. 2021; 20(2): 651-669.

PubMed Abstract | Publisher Full Text | Free Full Text

10. Nouvellet $P$, Bhatia $S$, Cori $A$, et al.: Reduction in mobility and COVID-19 transmission. Nat. Commun. 2021; 12(1): 1-9.

11. The WHO Rapid Evidence Appraisal for COVID-19 Therapies (REACT) Working Group: Association between Administration of Systemic Corticosteroids and Mortality among Critically III Patients with COVID-19: A Meta-analysis. JAMA. 2020; 324(13): 1330-1341.

12. Leentjens J, van Haaps TF, Wessels PF, et al:: CovID-19-associated coagulopathy and antithrombotic agents-lessons after 1 year. Lancet Haematol. 2021; 8(7): e524-e533. PubMed Abstract | Publisher Full Text | Free Full Text

13. Izcovich A, Ragusa MA, Tortosa F, et al.: Prognostic factors for severity and mortality in patients infected with COVID-19: A systematic review. PLoS One. 2020; 15(11): e0241955. PubMed Abstract | Publisher Full Text | Free Full Text

14. Document sobre l'actuació urgent en temps de la COVID-19: Consell Assessor del Pla Nacional d'Urgències. Published 2021. Accessed July 7, 2021. Reference Source

15. Protocol d'atenció a les persones amb infecció per SARS-CoV-2 a l'atenció primària. Barcelona: Departament de Salut; Published 2020. Accessed July 7, 2021 Reference Source

16. Borras-Bermejo B, Martínez-Giménez X, Miguel MGS, et al. Asymptomatic SARS-CoV-2 infection in nursing homes, 
Barcelona, Spain, April 2020. Emerg. Infect. Dis. 2020; 26(9): 2281-2283.

PubMed Abstract | Publisher Full Text | Free Full Text

17. Estrategia de vacunación frente a COVID-19: Actualizaciones. Published 2020. Accessed July 7, 2021 Reference Source

18. Dades COVID: Salut. Published 2020. Accessed July 7, 2021 Reference Source

19. Estrategia estatal contra la segunda ola: Ministerio de Sanidad. Published 2020. Accessed July 7, 2021. Reference Source

20. Monterde $\mathrm{D}$, Vela $\mathrm{E}$, Clèries $\mathrm{M}$, et al.: Multimorbidity as a predictor of health service utilization in primary care: A registry-based study of the Catalan population. BMC Fam. Pract. 2020; 21(1): 39. PubMed Abstract | Publisher Full Text | Free Full Text

21. Monterde $D$, Vela $E$, Clèries M: Los grupos de morbilidad ajustados: nuevo agrupador de morbilidad poblacional de utilidad en el ámbito de la atención primaria. Aten. Primaria. 2016; 48(10): 674-682.

PubMed Abstract | Publisher Full Text | Free Full Text

22. Gómez Jiménez J, Murray MJ, Beveridge R, et al.: Implementation of the Canadian Emergency Department Triage and Acuity Scale (CTAS) in the Principality of Andorra: Can triage parameters serve as emergency department quality indicators?. Can. J. Emerg. Med. 2003; 5(5): 315-322.

23. Funció dels gestors COVID a l'atenció primària en la fase de represa partir de la segona onada. Departament de Salut; Published 2020. Accessed July 7, 2021.

Reference Source
24. Català $\mathrm{M}, \mathrm{Coma} \mathrm{E}$, Alonso $\mathrm{S}$, et al.: Risk Diagrams Based on Primary Care Electronic Medical Records and Linked Real-Time PCR Data to Monitor Local COVID-19 Outbreaks During the Summer 2020. Front. Public Health. 2021; 9: 693956. Publisher Full Text

25. Evaluación Rápida del Riesgo: Circulación de variantes de SARS-CoV-2 de interés para la salud pública en España. Centro de Coordinación de Alertas y Emergencias Sanitarias; Published 2021. Accessed July 7, 2021. Reference Source

26. Pla de contingència per a residències per a la tardor de 2020. Departament de Salut; Published 2020. Accessed July 7, 2021 Reference Source

27. Cabezas-Peña C, Lejardi Y, Martínez-Marcos M, et al.: Vacunació COVID-19 Guia d'actuació Residències. Published 2021. Accessed July 7, 2021. Reference Source

28. Booth A, Reed AB, Ponzo S, et al.: Population risk factors for severe disease and mortality in COVID-19: A global systematic review and meta-analysis. PLoS One. 2021; 16: e0247461. PubMed Abstract | Publisher Full Text | Free Full Text

29. Tarighi $\mathrm{P}$, Eftekhari S, Chizari M, et al.: A review of potential suggested drugs for coronavirus disease (COVID-19) treatment. Eur. J. Pharmacol. 2021; 15(895): 173890.

30. Cossio Gil Y, et al.: Comparing the first and second waves of COVID-19 in a tertiary university hospital in Barcelona, Dryad. Dataset. 2021.

Publisher Full Text 


\section{Open Peer Review}

\section{Current Peer Review Status:}

\section{Version 1}

Reviewer Report 03 August 2022

https://doi.org/10.5256/f1000research.77690.r143966

(c) 2022 Frediansyah A. This is an open access peer review report distributed under the terms of the Creative Commons Attribution License, which permits unrestricted use, distribution, and reproduction in any medium, provided the original work is properly cited.

\section{Andri Frediansyah}

National Research and Innovation Agency (BRIN), Jakarta Pusat, Indonesia

Cossio et al. investigated the flow of COVID-19 patients in emergency rooms and hospital wards in Barcelona, Spain, between the first and second waves of the pandemic. Additionally, they compared the severity and mortality profiles of COVID-19 patients from the two waves. The entire manuscript is well-written, and the methodology is well-executed. Therefore, I suggest indexing after the following minor revisions:

1. Please define ICD-10-CM in the introductory paragraphs.

2. Please include some hospital-improved strategies as the hospital also improves its facilities after the first wave.

3. Please include the limitations of the study.

4. Please specify the hospital's COVID-testing procedures.

5. Some of the references listed below may be useful for discussing the results.

\section{References}

1. Asghar MS, Yasmin F, Haris A, Nadeem A, et al.: Comparison of first and second waves of COVID19 through severity markers in ICU patients of a developing country.J Community Hosp Intern Med Perspect. 2021; 11 (5): 576-584 PubMed Abstract | Publisher Full Text

2. Balacchi C, Brandi N, Ciccarese F, Coppola F, et al.: Comparing the first and the second waves of COVID-19 in Italy: differences in epidemiological features and CT findings using a semiquantitative score.Emerg Radiol. 2021; 28 (6): 1055-1061 PubMed Abstract | Publisher Full Text 3. Iftimie S, López-Azcona AF, Vallverdú I, Hernández-Flix S, et al.: First and second waves of coronavirus disease-19: A comparative study in hospitalized patients in Reus, Spain.PLoS One. 2021; 16 (3): e0248029 PubMed Abstract | Publisher Full Text

4. Akande OW, Elimian KO, Igumbor E, Dunkwu L, et al.: Epidemiological comparison of the first 
and second waves of the COVID-19 pandemic in Nigeria, February 2020-April 2021.BMJ Glob Health. 6 (11). PubMed Abstract | Publisher Full Text

5. Buttenschøn HN, Lynggaard V, SandbøI SG, Glassou EN, et al.: Comparison of the clinical presentation across two waves of COVID-19: a retrospective cohort study.BMC Infect Dis. 2022; 22

(1): 423 PubMed Abstract | Publisher Full Text

6. Soriano V, Ganado-Pinilla P, Sanchez-Santos M, Gómez-Gallego F, et al.: Main differences between the first and second waves of COVID-19 in Madrid, Spain.Int J Infect Dis. 2021; 105: 374376 PubMed Abstract | Publisher Full Text

7. Jana KR, Yap E, Janga KC, Greenberg S: Comparison of Two Waves of COVID-19 in Critically Ill Patients: A Retrospective Observational Study.Int J Nephrol. 2022; 2022: 3773625 PubMed Abstract | Publisher Full Text

Is the work clearly and accurately presented and does it cite the current literature? Yes

Is the study design appropriate and is the work technically sound?

Yes

Are sufficient details of methods and analysis provided to allow replication by others? Yes

If applicable, is the statistical analysis and its interpretation appropriate? Yes

Are all the source data underlying the results available to ensure full reproducibility? Yes

Are the conclusions drawn adequately supported by the results?

Yes

Competing Interests: No competing interests were disclosed.

Reviewer Expertise: Pharmacology and Microbiology

I confirm that I have read this submission and believe that I have an appropriate level of expertise to confirm that it is of an acceptable scientific standard.

Reviewer Report 13 July 2022

https://doi.org/10.5256/f1000research.77690.r143967

(c) 2022 Mantica G. This is an open access peer review report distributed under the terms of the Creative Commons Attribution License, which permits unrestricted use, distribution, and reproduction in any medium, provided the original work is properly cited.

\section{Guglielmo Mantica}


IRCCS Ospedale Policlinico San Martino, Genova, Italy

This is an interesting manuscript about the difference between ED admissions between first and second wave at a hospital in Barcelona, Spain. The abstract and introduction are well written. Methods are well designed and clear.

Here some minor concerns:

"The study included 8,684 distinct COVID-19 patients who attended the emergency rooms (ER) and/or were hospitalised." This is already a result. Please move it to the correct section.

Please specify in the methods if in your hospital there have been differences/changes in COVID swab tests during the two different waves (type of diagnostic test) since this might lead to differences in the correct identification of patients.

Please expand and declare all limitations.

Some authors found differences between admissions during the first and second waves also for Non Covid patients (doi: 10.1016/j.ajem.2020.11.046.). Do you have any data available from your hospital? Otherwise just make a comment in the discussion session.

\section{References}

1. Mantica G, Riccardi N, Terrone C, Gratarola A: Non-COVID-19 admissions to the emergency department during the pandemic second wave in Italy: What is changed from the first wave?. The American Journal of Emergency Medicine. 2021; 45: 625-626 Publisher Full Text

Is the work clearly and accurately presented and does it cite the current literature? Yes

Is the study design appropriate and is the work technically sound?

Yes

Are sufficient details of methods and analysis provided to allow replication by others? Yes

If applicable, is the statistical analysis and its interpretation appropriate? Yes

Are all the source data underlying the results available to ensure full reproducibility? Yes

Are the conclusions drawn adequately supported by the results? Yes

Competing Interests: No competing interests were disclosed.

Reviewer Expertise: Urology 
I confirm that I have read this submission and believe that I have an appropriate level of expertise to confirm that it is of an acceptable scientific standard.

The benefits of publishing with F1000Research:

- Your article is published within days, with no editorial bias

- You can publish traditional articles, null/negative results, case reports, data notes and more

- The peer review process is transparent and collaborative

- Your article is indexed in PubMed after passing peer review

- Dedicated customer support at every stage

For pre-submission enquiries, contact research@f1000.com 